\title{
The Absence of ESL Students' Voices in Education
}

Yeonjung (Judy) Lee

Simon Fraser University

\begin{abstract}
"To enable learners of ESL means... ensuring equity of educational opportunity for all students. As educators, we celebrate the diversity of our student population, and wish to promote a climate of acceptance and respect for all” $\quad$ (ESL Advisory Committee Report, 1990).
\end{abstract}

"The question at hand is how we can best respond to student diversity so that standards are upheld for every student, including the most difficult to teach and most challenging to motivate” (Wang, 1994).

Canada's classrooms are becoming increasingly diverse with a fast-growing school population of students whose first language is not English. They are English as Second Language (ESL) students; each pupil is an English Language Learner (ELL). Since 1990, the number of students identified as needing ESL services in British Columbia has more than tripled. These students face challenges in keeping pace academically and learning a new language. The challenge is especially great when students are placed in mainstream English-language classrooms before they develop their language proficiency. With its focus on the development of academic skills, the ESL curriculum may not be providing enough support to help ELLs fully participate in mainstream English classes. The lack of support will result in unequal access to high-quality learning opportunities and cultural gaps within schools. English language learners (often referred to as ESL students) may become marginalized and may prematurely reach a plateau in their English acquisition.

\section{Introduction}

English language learners are those whose primary language, or languages, are other than English. These students need additional services to develop their individual potential within British Columbia's school systems. The primary goal of provincial education is to support the intellectual development of students. Enabling students to 
achieve the goals of human and social development and career development is a responsibility shared by schools, families, and the community (British Columbia Ministry of Education 2009). These goals apply equally to English as Second Language learners. However, despite the growth of ESL services, increasing numbers of students appear to suffer from a variety of problems and obstacles when making the transition from an ESL class to a mainstream learning environment. The pupils encounter difficulties with socialization and confidence as well as communicative and academic competence.

This paper argues that ESL student voices are neither adequately heard nor reflected in the discussion of ESL education. Instead, educators and researchers spend excessive amounts of time focusing on theories, instructional methods, materials, and program evaluation. The biggest challenge is that the ESL curriculum, with its focus on academic skills development, may not be providing enough support to help learners incorporate into mainstream English classes. Schools use standardized tests to assess when students can be placed in mainstream classes. However, these tests do not help educators to gauge students' ability to learn.

This paper is organized into four sections. The first section of the paper seeks to inform the reader about the goals and different structures of the ESL program in schools. Schooling outcomes of ESL students in Canada will be introduced in the second section of the paper toward demonstrating that the ESL programs are not meeting the students' needs. Personal experience as well as ESL students' stories of their experiences will be introduced in the third section of the paper as an integral part of understanding the educational values of the current ESL curriculum and to have a clear understanding of what really matters to ESL students. Finally, in the fourth section, an analysis of personal experience using 
Schwab's four commonplaces is described to point to areas that need further enhancement to support the academic progress of English Language Learners.

\section{The Goal of the ESL Program and Different Models}

ESL students must meet graduation requirements. If the learners cannot demonstrate expected learning outcomes of the provincial curriculum, school districts ensure that appropriate ESL services, including English language instruction, are provided. The purpose is to assist students to become proficient in English, to develop both intellectually and as citizens, and to achieve the expected learning outcomes of the provincial curriculum. These services reflect community values of diversity and culturallyinclusive, non-racist education. Over time it is expected that support levels will diminish as a student progresses successfully in a fully integrated program (Ministry of BC Education). Furthermore, British Columbia's policy on ESL clearly states that ESL instruction is designed to enable students to master the provincial curriculum:

ESL will be offered as a transitional [service] to ensure the successful integration of these students into regular classes as soon as possible. The goal of ESL education is to assist students to become proficient in English, to develop intellectually and as citizens and to enable them to achieve the expected learning outcomes of the provincial curriculum (Government of BC 1996, passim).

As a former ESL student in the BC education system, I have experienced these ESL programs. In some schools, the basic program takes the form of pulling-out students from regular classes according to a learner's level of language proficiency. In other cases, beginner, intermediate, and advanced level classes are offered. The students must pass every level up through to advanced enabling them to join regular classes, including the mainstream English class. 
There is considerable debate about the effectiveness of the different models of ESL programs. Take for example the pull-out system where students may have a more effective learning experience in separate focused groups in the pull-out ESL classroom. Students are taken out of their classes for one or two periods a day to receive ESL instruction in smaller class sizes with students of similar proficiency levels. Ideally, the ESL teachers provide the needed support for students to be successful in the mainstream classroom. Support can include intensive vocabulary and grammar instruction. An advantage of studying in this system is that the teacher communicates at a language level that is appropriate to the students' level of English, and fosters a personal relationship with students, who, in the early days in school, may feel lost and confused. On the other hand, one disadvantage of the ESL pull-out is that students will miss class work and the separation will create difficulty in socializing with Canadian friends and teachers. Also, their self-esteem may be diminished as it reduces opportunities for the meaningful use of English in class work (Sears, 1998). At minimum, ESL teachers conducting pull-out classes must work closely with classroom teachers so that the students are not being graded on missed work.

\section{Schooling Outcome of ESL Students in Canada}

Although the ultimate goal of ESL programs is to help learners become socially and academically competent so that they can fully integrate in the mainstream classes, Canadian researchers have suggested that schools do not serve ESL students well. Some students withdraw from specific academic courses while others are at risk of failure and dropping out of school entirely (Toohey \& Derwing, 2006). For example, researchers at the University of British Columbia reported, in 1998, with respect to BC ESL students, that instead of improving over the past 15 years, immigrant students' dropout rates had 
increased and their achievement had declined. According to Gunderson's recent comprehensive study of 24,890 immigrant secondary students enrolled in Vancouver public schools between 1991 and 2001, it was shown that the number of ESL students in provincially-examinable courses decreased significantly from Grades 8-12. ESL students were not registering in the courses that would lead them to post-secondary school career options or they were dropping out of school altogether (Gunderson, 2004). The disappearance rate of ESL students was predominantly high, especially the children of less affluent parents. He noted that parents who employed multiple tutors for the students persevered in academic subjects at much higher rates. He concluded:

Students who drop out of school are likely to be from socio-economically disadvantaged circumstances. And, as indicated by the study reported here of Vancouver immigrant students, the more subtle measure of enrollment in "academic stream courses," courses students must take to be admissible to a university or college, confirmed that immigrant students were "disappearing" from such courses as well, reducing their chances for higher education and all the benefits that come from such (Gunderson, 2004, p.18).

Another BC study was done by Duff (2001) in which she observed two mainstream Grade 10 Social Studies classes and interviewed the teachers and the students. She found out that teachers had insufficient time to support ESL students and made little effort toward helping them to adjust socially. Consequently, the ESL students lacked the linguistic ability and cultural and geographical knowledge required to interpret written texts; they had missed earlier grades where the same topics were covered at a more superficial level, and their own cultural, academic and background knowledge was not included in the curriculum (Toohey \& Derwing, 2006). Furthermore, Duff observed that ESL students were at a disadvantage in understanding class instruction since it was too fast and because they were unfamiliar with North American culture and traditions. Duff concluded, 
"Therefore, to learn effectively in this context and to become an active member of the classroom discourse community, students' 'social' communication, interaction skills, and cultural knowledge seemed to be as important as their 'academic' proficiency" (p. 118).

Although a higher percentage of ESL students in BC graduate than their Englishspeaking peers, ironically, many ESL students write few provincial examinations in examinable subjects (Toohey\&Derwing, 2006). Exams for graduation requirement courses are written often, but exams for courses such as French and History are not. The students could have developed valuable knowledge about the country and its traditions by taking history courses. Even when the course is not about Canadian history, the courses are taught from a Canadian perspective, which can help the students understand and participate in Canadian society. In the Toohey and Derwing studies, students were more likely to write provincial examinations in subjects that have a strong visual or quantitative component, like Math and Chemistry.

The results of the Gunderson (2004), Duff (2001), and Toohey and Derwing (2006) studies clearly suggest that the primary goal of ESL programs may not have been to accommodate ESL students' needs. Furthermore, the ESL curriculum is not paying attention to what students are actually going through in their progression toward mainstream classes. Their voices are not reflected. The ESL programs appear not to meet the learners' need for academic skills nor support the students' incorporation into mainstream English classes.

\section{Personal Experience}

Being in an ESL classroom is not just about learning English. Participation also relates to the students' efforts to construct their identities and build their interpersonal 
relationships with other students. Students strongly believe that the ESL program will help them to achieve their goals for learning English in the mainstream classes. My research has found very little information on how students' feel about ESL classes and their perspectives on ESL education in a way that informs both theory and practice. In contrast, one can easily identify a large number of articles on ESL curriculum and teaching strategy seen from the perspective of teachers and researchers. This section of the paper will discuss my personal experience with ESL classrooms and ESL students whom I encountered in my school years. Their perspectives on ESL education offer the opportunity to understand more clearly what really matters to ESL students.

My family immigrated to Canada when I was 12 years old and we hoped to have a successful life. My parents strongly believed that I would have a good-quality education in Canada. My family settled in a neighborhood in Mission where the population was mostly white. I had just started learning English at that time and had very little fluency. I was placed in a mainstream Canadian classroom and I was the only Asian in the whole school. Since there were no other immigrant students or ESL students there was not enough demand to set up an ESL class. Thankfully, the school gladly offered ESL programming just for me. It was a pull-out structured ESL class; however, most days I was in the ESL classroom with the teacher the whole day focusing on my English skills.

With great support and devotion from my teachers, I completed the ESL program by grade 9 and transitioned to the mainstream classes. It greatly helped me to learn all areas of English including, listening, reading, writing, and speaking intensively as it was one-to-one instruction. However, there was not much time offered me to join the mainstream class and interact with Canadian school friends. The only time where I could participate with them 
was in relatively language-independent subjects such as physical education, arts, music and math. Reflecting on five years of ESL education, approximately two years in one-to-one instruction in Mission, and three years of pull-out ESL instruction in middle school in Coquitlam, I wish I could have spent more time in the mainstream class with Canadian peers to build relationships and have the opportunity to use daily spoken English. I felt as though there was little interaction between ESL and native-English-speaking students in my school. Although ESL students had an opportunity to build relationships, the level of fluency was limited and differed greatly from English-speaking students taking general courses.

The high school I went to had the largest population of immigrants and international students in Coquitlam. For a student to be identified as an English language learner, an assessment of English language proficiency must be carried out. Ideally, initial assessments are conducted upon a student's first arrival at school. Alternatively, assessment may be conducted at any point if there is an indication that there might be a need for ESL services. According to the Ministry of Education (2009), ESL placement should be determined by an ESL specialist in collaboration with the classroom teacher, other professionals as appropriate, as well as with the student and parents. Students should be placed in classroom settings where they can reasonably be expected to succeed. However, testing of international students may focus only on their English skill level. The level ranges from beginner through advanced. Students are then appropriately placed. From my experience, international students, whom I knew in my high school, thought they would be in ESL programs for only a short time, since they had already acquired English skills in their countries. Because these international students already had a good understanding of 
grammar and writing skills, they believed that taking ESL classes would help them to succeed in regular English class. Unfortunately, at the end of the school semester, these students were required to pass each level with a standardized test, which comprised of multiple choice test items based on the materials the students studied in class. They had to score at least $85 \%$ to pass the test; otherwise, they needed to repeat the level.

The drawback of using a standardized test approach is that regardless of how hard students work or how much they participated, those elements will not be included in the assessment, and the test could not be re-taken. In addition, students must complete each level until they reach the advanced ESL class before they can enroll in mainstream English classes. Therefore, the students felt as if they were trapped by an unfairly extensive ESL system, which delayed their graduation. The students who could not take English classes within their study period had to take it during summer school or worse, in night school.

On the other hand, students who pass ESL levels in a timely manner do not necessarily have a better understanding of English, since it is achieved by memorization. For example, while students may have memorized difficult vocabulary, many have difficulty explaining word meanings as well as the contexts in which the words are found. According to Stiggins (2002), the standardized tests that were "ostensibly developed to leave no student behind, are in fact causing major segments of our student population to be left behind" (p. 759). Indeed, students who do poorly on these tests may give up on schooling.

Another problem is that there seems to be wide incongruity between ESL programs and English classes. Based on the practice that I observed, the students who were able to be in regular English class suggested that the ESL curriculum did not help them at all in 
preparing for regular class. Most days, the teacher distributed reading sheets along with fillin-the-blank exercise sheets, had them copy down writings in their notebook, had them memorize vocabulary for tests, and assigned comprehension reading question. Students felt they did not receive strong support on English skills from their teacher, and there was not enough communication happening between the students and the teacher.

\section{Analysis of ESL Experience by Schwab's Four Commonplaces}

Schwab (1978) offers one possible solution to the lack of integration in both ESL programs and mainstream education. Schwab's (1978) model is an integrative tool to conceptualize teacher education curricula; it addresses four aspects of education: the learner, the teacher, the subject matter, and the social milieu.

\section{Learner}

ESL students value connecting with peer groups. The value of learning English is highly dependent on whose friendship they seek, and which group they associate with. For example, a Japanese ESL student named Ritsuko, who arrived in Toronto with high motivation to learn English and to integrate into the native English speakers' community, lost her determination to improve her English when she understood that no effort on her part would open the door to the community (Kanno \&Applebaum, 1995). Just like Ritsuko's case, ESL students travel abroad with highly motivated to learn English and expect to compete academically with native English speakers, successfully assimilating into the mainstream community. But as soon as the students realize the difficulty of assimilating, many students may lose their self-motivation and give up on their education. 


\section{Subject Matter}

International students in my high school felt that the ESL program obstructed their integration in mainstream studies, since ESL programs separated them from their Canadian peers. The discrepancy between theory and practice may be largely due to an inadequate assessment of current ESL students' needs (Kanno \&Applebaum, 1995). In order to provide ESL students with equal access to mainstream curriculum and support language development, it is crucial to effectively monitor ESL students' progress. Assessment needs to be continuous, using procedures that promise to provide the most useful information regarding the nature and quality of classroom instruction. Effective assessment strategies do not depend upon multiple-choice test scores or rigid practices, but require diligent application in light of the large population of English Language Learners (ELLs) in schools. Assessment must be carefully designed, administered, and practiced in the interest of ELLs. Schools need to ensure that assessments are valid and useful through working groups of ELL specialists and assessment specialists to develop, monitor, and revise the assessment programs.

ESL instruction should not separate learners from mainstream students and should not have to be debasing to the students' cognitive abilities. Furthermore, the subjects must be interconnected with the learning material of the mainstream classroom. Early et al. (1989) argue that:

It needs to support students the gap between beginning social acquisition and full social and academic linguistic competency in mainstream classroom is a carefully articulated approach and program which integrates the teaching of language and the teaching of subject area knowledge ( $\mathrm{p}$. 108). 
Schools and educators must acknowledge that the ultimate goal of ESL students is not just learning English, but to achieve their academic goals successfully in the mainstream classes. In order to achieve this, the school must move beyond the approach that English learning must precede proper content learning and seek possibilities to combine both in the integrated curriculum. Then, students can not only achieve their learning goals and make a smooth transition to the mainstream, but it will help reduce their isolation from native-speaking peers (Kanno\&Applebaum, 1995).

\section{Teachers}

A teacher's care for her students can make a significant difference in students' grades and behavior. Researchers Deiro (1996) and Noddings (1992) have found that once students recognize their teacher's genuine care, the relationship considerably influences their grades, class work, homework, attitude, motivation, and behavior. Furthermore, when teachers clearly care about their students, students' attitudes and behavior change in a positive way, because they want to please those who care about them. As a result, students work harder, increase their learning, and strive for success in school (Noddings, 1992 \& Deiro, 2003). In addition, understanding a student's background and cultural difference is essential. Consultation with other professionals can be accomplished if teachers have genuine care.

Personally, I had a hard time raising my hand and sharing my thoughts in the class, because I was used to studying in an environment where there was no interaction between teachers and students; instead, the teacher just presented the course content. Moreover, it was considered rude to raise a hand in the middle of the teacher's lecture. Upon entering school in Canada, I was very surprised to be in an environment where there was active 
involvement and class interaction between the teacher and students. In fact, this cultural difference made me fearful about speaking up. However, one day, my teacher opened a lesson about different languages spoken in the world and told the students that I could speak in Korean. She encouraged me to share the Korean language in the class and asked me to write down some of the students' names in Korean. Seeing my teacher's care and encouragement, I gradually raised my voice in the class. The teacher's role is important since teachers can create a setting where students can be actively involved.

Unfortunately, few mainstream teachers have been prepared to address the linguistic challenges and cultural differences present in diverse classrooms, and significant numbers of mainstream teachers may find it difficult to create a truly welcoming atmosphere for ESL students (Youngs \& Youngs, 2001). In addition, there are no provincial ESL requirements for public school teachers, and many ESL learners are now taught by teachers who have no training at all in second language education techniques and approaches. To immediately address this unsustainable issue, enhanced professional training development opportunities must be available to prepare teachers to teach culturally and linguistically diverse students and reconsider their own motivation.

\section{Social Milieu}

School provides both liberation and domination for ESL students. It is a site of liberation, because ESL students are situated in a safe place where they can take risks and build new relationship with friends and teachers, and gain experience with their new language without feeling threatened by the prospect of failure. On the other hand, it is a site of domination, because relegating students to ESL programs makes them second-rate citizens of the school and lessens their motivation to advance their English beyond the level 
required in the ESL environment (Kanno \&Applebaum, 1995). However, school can make a positive difference in successfully integrated students. I had a hard time learning two languages and accommodating to two different cultures; however, it was through these experiences that I was able to develop a strong Korean-Canadian identity and achieve academic success. Spending my time in Canadian school, I gradually realized that belonging to multiple cultures is a blessing and an opportunity to broaden knowledge and become bilingual. The school must bring the students together and achieve integration not only for the sake of ESL students; it should also prepare students for the cultural and linguistic diversity that is rapidly becoming a fact of life in the country they live in (Kanno \&Applebaum, 1995).

\section{Conclusion}

It is very different to see the results of an ESL curriculum from the perspective of ESL students than from the perspective of the educational system. What ESL students really need is education that supports them in building their language competency in a mainstream classroom. However, it becomes clear that the goal of ESL program and ESL curriculum are unsuccessful in helping the students' integration into the mainstream classroom, personal and educational growth. Without knowing the student's perspectives, it is impossible to structure an effective ESL curriculum. Students contribute much to shape their learning, and they are capable of responding to more challenges in learning. 


\section{References}

British Columbia Ministry of Education. (2009). English as a second language: Policy and guideliness. Retrieved from http://www.bced.gov.bc.ca/esl/policy/guidelines.pdf

Deiro, J. A. (2003). Do your students know you care? Educational Leadership, 60(6), 6062.

Duff, P.A. (2001). Language, literacy, content, and (pop) culture: Challenges for ESL students in mainstream courses. Canadian Modern Language Review 58: 103-32.

Early, M., Mohan, B.A., \& Hooper, H.R (1989). The Vancouver school board language and content project. In J.H. Esling (Eds.), Multicultural education and policy: ESL in the 1990s (pp.107-122). Toronto, ON: OISE Press.

Government of British Columbia. (1996). Language education in BC schools: Policy and guidelines. Victoria.

Gunderson, L. (2004). The language, literacy achievement, and social consequences of English-only programs for immigrant students. National Reading Conference Yearbook 53: 1-27.

Kanno, Y., \& Applebaum, S.D. (1995). ESL students speak up: Their stories of how we are doing. TESL Canada Journal. 12(2):32-49.

Miller, P. \& Endo, H. (2004). Understanding and meeting the needs of ESL students. Phi Delta Kappan, 85(10), 786-791.

Noddings, N.(1992). The challenge to care in schools: An alternative approach to education. NY, NY: Teachers College Press.

Sears, C. (1998). Second language students in mainstream classrooms: A handbook for teachers in international schools. Clevedon: Multilingual Matters.

Stiggins, R. J.(2002). Assessment crisis: The absence of assessment for learning. Phi Delta. Kappan. 83(10), 758-765.

Toohey, K. and Derwing, T.M. (2006). Hidden losses: How demographics can encourage incorrect assumptions about ESL high school students' success. Research on Immigration and Integration in the Metropolis, 6(11):1-25.

Youngs, C.S., \& Youngs, G.A. (2001). Predictors of mainstream teachers' attitude toward ESL students. TESOL Quarterly, 35:97-120. 